\title{
A Study on Retinitis Pigmentosa as a Cause of Blindness in Patients Attending Regional Eye Hospital, Kurnool for Blind Certificate
}

\author{
Dr.K.Anjaneyulu ${ }^{1}$,Dr.G.Narendranath Reddy ${ }^{2}$,Dr.T.Madhuri ${ }^{3}$,Dr.Vijay Kanth ${ }^{4}$ \\ Ophthalmology Department,Kurnool Medical College, Kurnool Andhra Pradesh, India
}

\begin{abstract}
Background: To study Retinitis Pigmentosa as a cause of blindness in patients attending Regional Eye Hospital, Kurnool for blind certificate

Methods: A total of 370 patients of all age groups attending to Regional Eye Hospital, Kurnool for blind certificate during the period June 2015 to June 2016 were included and examined which include visual acuity testing using Snellen chart, refraction, slitlamp biomicroscopy, intra ocular pressure measurement using Goldmann Applanation Tonometer, fundus examination with indirect ophthalmoscope, visual field testing using Humpry field analyser. Fundus picture was taken using Zeiss fundus camera. Patients having retinal pathology were exclusively included in the study and others were excluded.

Results: Out of 370 patients, 29 patients had Retinitis Pigmentosa with involvement of both eyes. Of these 29 patients, 18 were males and 11 were females indicating that males were more commonly affected than females. 18 patients had 100\% disability, 7 patients had 75\% of disability, 4 patients had $40 \%$ of disability.

Conclusion: Retinitis Pigmentosa is one among the non treatable cause of blindness which result due to consanguinity marriages as it is an inherited eye disease.
\end{abstract}

Keywords: Retinitis Pigmentosa, blindness, consanguinous marriage, inherited disease.

\section{Introduction}

Blindness is a major public health problem in developing countries like India ${ }^{(1,2)}$.Some ocular diseases are treatable and others are not. Non-treatable diseases lead to permanent visual handicap which affect an individual, his/her family and the society. The registration as blind/low vision in India is voluntary and it is certified by an ophthalmologist. According to guidelines of the Ministry of Social Justice and Empowerment, Government of India, the minimum degree of disability should be $40 \%$ for an individual to be eligible for any concessions or benefit ${ }^{[3]}$.

Among the non treatable causes of retinal blindness, Retinitis Pigmentosa is one causing permanent blindness. Retinitis Pigmentosa (RP) is an inherited, degenerative eye disease that causes severe vision impairment ${ }^{[4]}$ due to the progressive degeneration of the rod photoreceptor cells in the retina. This form of retinal dystrophy manifests initial symptoms independent of age; thus, RP diagnosis occurs anywhere from early infancy to late adulthood. ${ }^{[5]}$ Patients in the early stages of RP first notice compromised peripheral and dim light vision due to the decline of the rod photoreceptors. ${ }^{[6]}$ The progressive rod degeneration is later followed by abnormalities in the adjacent retinal pigment epithelium (RPE) and the deterioration of cone photoreceptor cells the disease causes blind spots to develop in the side (peripheral) vision. As peripheral vision becomes increasingly compromised, patients experience progressive "tunnel vision" and eventual blindness. ${ }^{[7]}$. In adulthood, many people with retinitis pigmentosa become legally blind. Affected individuals may additionally experience defective light-dark adaptations, nyctalopia (night blindness), and the accumulation of bone spicules in the fundus.

\section{Materials And Methods}

The present study was conducted on 370 patients who attended regional eye hospital, Kurnool for blind certificate during the period june 2015 to june 2016.Patients of all age groups were included in the study. All the patients who were included in the study underwent visual acuity testing using Snellen chart. Distance and near visual acuity, both presenting and best corrected after refraction, were measured for each eye separately using Snellen chart $^{(8)}$. Objective refraction was performed with a streak retinoscope, followed by subjective acceptance with which the best-corrected acuity was measured and recorded. External eye examination,assessment of pupillary reaction, and anterior segment examination were done with slitlamp biomicroscope, intra ocular pressure measurement using Goldmann Applanation Tonometry. All participants had their pupils dilated and after dilatation the lens was examined with the slitlamp and nuclear cataract was 
graded according to the Lens Opacities Classification System III $^{(9)}$ and cortical and posterior subcapsular cataracts were graded using the Wilmer classification ${ }^{(10)}$. Stereoscopic fundus examination, including assessment of the vitreous, retina, and optic disc, was done at the slitlamp using 78 diopter lens and with the indirect ophthalmoscope using 20 diopter lens. Automated visual fields were done with the Humphrey visual field analyzer ${ }^{(11)}$ using the central 24-2 threshold strategy in those participants assessed to have any suspicion of retinitis pigmentosa. Fundus picture was taken using Zeiss fundus camera in patients with retinitis pigmentosa.

\section{Results}

Table 1 : Effect of age and sex

\begin{tabular}{|l|l|l|l|}
\hline Age & Males & Females & Total \\
\hline $0-10$ & 1 & 1 & $2(6.89 \%)$ \\
\hline $11-20$ & 3 & 4 & $7(24.13 \%)$ \\
\hline $21-30$ & 6 & 3 & $9(31.03 \%)$ \\
\hline $31-40$ & 3 & 1 & $4(13.79 \%)$ \\
\hline $41-50$ & 1 & 2 & $3(10.34 \%)$ \\
\hline$>50$ & 4 & 0 & $4(13.79 \%)$ \\
\hline & $18(62.06 \%)$ & $11(37.94 \%)$ & $29(100 \%)$ \\
\hline
\end{tabular}

Table 2 : percentage disability according to sex

\begin{tabular}{|l|l|l|l|l|}
\hline & $40 \%$ & $75 \%$ & $100 \%$ & Total \\
\hline Males & 3 & 4 & 11 & $18(62.06 \%)$ \\
\hline Females & 1 & 3 & 7 & $11(37.94 \%)$ \\
\hline & 4 & 7 & 18 & $29(100 \%)$ \\
\hline
\end{tabular}

\section{Discussion}

Blindness defined as presenting visual acuity $<6 / 60$ in the better eye; Best corrected visual acuity $<3 / 60$ and/or less than 10 degree visual field in better eye. Among the retinal causes of blindness, retinitis pigmentosa constitute one of the non treatable cause of blindness . In our study conducted on 370 patients, 29 patients were found to have retinitis pigmentosa. Of these 29 patients, $18(62.06 \%)$ were males and $11(37.94 \%)$ were females indicating that retinitis pigmentosa is more common among males compared to females. $9(31.03 \%)$ among 29 persons were found between the age group 21-30 indicating that it was the most common age group to be involved.

Regarding the percentage of disability, 4 patients had $40 \%$ disability, of which 3 were male patients and 1 female patient. 7 patients had $75 \%$ disability of which 4 patients were males and 3 were females. 18 patients had $100 \%$ disability of which 11 were males and 7 were females. A study conducted by Joshi et al reported that retinitis pigmentosa constituted $15.05 \%$ of blindness amongst patients attending outpatient department of a medical college for visual handicap certification in central India ${ }^{(12)}$.

A study done on RP patients in various states of India has shown an autosomal-recessive, predominant inheritance pattern, and more than $92 \%$ of cases in autosomal-recessive category had positive history of consanguinity ${ }^{(13)}$. RP is a major cause of blindness in Southern India, with a prevalence of 1 in 1000 in the state of Andhra Pradesh ${ }^{(14)}$. Clinically, patients with history of consanguinity in the family showed maximum number of early onset severe case. Although the number of patients with AR non consanguineous pattern was too small, early and senile onset of disease was not seen. The patients of AR(D) type of inheritance had characteristic symptoms of headache, giddiness flashes of light and worsening of symptoms after any stress or strain. Similar observations have been reported by others in RP patients. ${ }^{[15],[16],[17],[18]}$ This group of patients could have congenital onset of the disease and also generally developed cataracts, as opposed to AR(R) group where cataracts were a rarity and congenital cases were not seen. The autosomal dominant patients had slowly progressive disease taking over $10-15$ years. ${ }^{[19]}$

\section{Conclusion}

Retinitis pigmentosa as an inherited disease runs in the families need utmost care to reduce the burden on prevalence of blindness as it is one among the non treatable cause of blindness and as there are no specific treatment modalities to cure. Hence we need to concentrate on genetic counseling to reduce consanguinous marriages.

\section{References}


[1]. Schémann JF, Leplège A, Keita T, Resnikoff S. From visual function deficiency to handicap: Measuring visual handicap in Mali. Ophthalmic Epidemiol 2002;9:133-48.

[2]. WHO study group. The prevention of blindness. WHO Technical Report Series No. 518, 1973. Available from: htt p://whqlibdoc.who.int/trs/WHO_TRS_518.pdf [last accessed on 2016. August 29].

[3]. Guidelines for the evaluation of various disabilities and procedures for certification. The Gazette of India extraordinary Part 1; Section 1: No 154.Avialable from: http://www.ccdisabilities.nic.in/eval2/page6.htm [last accessed on 2016. August 30].

[4]. 4"Bardet-Biedl (Laurence Moon)"

[5]. Koenekoop, Robert K; Loyer, Magali; Hand, Collette K; Al Mahdi, Huda; Dembinska, Olga; Beneish, Raquel; Racine, Julie; Rouleau, Guy A (2003). "Novel RPGR mutations with distinct retinitis pigmentosa phenotypes in French-Canadian families". American Journal of Ophthalmology. 136 (4): 678-87

[6]. Understanding Retinitis Pigmentosa

[7]. Farrar, G.J.; Kenna, P. F.; Humphries, P (2002). "NEW EMBO MEMBer's REVIEW: On the genetics of retinitis pigmentosa and on mutation-independent approaches to therapeutic intervention". The EMBO Journal. 21 (5): 857-64.

[8]. Ferris FL, Kassoff A, Bresnick GH, Bailey I. New visual acuity charts for clinical research. Am J Ophthalmol. 1982;94:9196. [CrossRef][PubMed]

[9]. Chylack LT, Wolfe JK, Singer DM, et al. The lens opacities classification system III. Arch Ophthalmol.1993;111:831-836.

[10]. Taylor HR, West SK. A simple system for the clinical grading of lens opacities. Lens Res. 1988;5:175-181.

[11]. Humphrey Field Analyzer II User's Guide. San Leandro: Humphrey Instruments Inc, 1994. 9

[12]. Joshi RS. Causes of visual handicap amongst patients attending outpatient department of a medical college for visual handicap certification in central India. Journal of Clinical Ophthalmology and Research 2013;1(1):17-

[13]. Vinchurkar MS, Sathye SM, Dikshit M. Retinitis pigmentosa genetics: A study in Indian population. Indian J Ophthalmol 1996;44:77-82

[14]. Dandona L, Dandona R, Srinivas M, et al. Blindness in the Indian state of Andhra Pradesh. Invest Ophthalmol Vis Sci. 2001;42(5): $908-916$.

[15]. Kaplan J, Bonneau D, Fre'zal J. et al. Clinical and genetic heterogeneity in Retinitis pigmentosa. Hum. Genet 85:635-42,1990.

[16]. Foxman SG, Heckenlively JR, Bateman JB., et al. Classification of congenital and early onset RP. Arch Ophthalmo 103:15026,1985 .

[17]. Gawande AA, Donovan WJ, Ginsburg AP, et al.Photoaversion in RP. Br J Ophthalmol,73:337-41,1989.

[18]. Fishman G. A Retinitis Pigmentosa: visual loss. Arch Ophthalmol 96:1185-88, 1978.

[19]. Fishman GA. Retinitis pigmentosa:genetics percentages. Arch. Ophthalmol,96:822-26. 